\title{
Pimecrolimus cream in the management of patients with atopic eczema
}

This article was published in the following Dove Press journal:

Clinical, Cosmetic and Investigational Dermatology

15 May 2009

Number of times this article has been viewed

\section{Jonathan M Spergel}

Division of Allergy and Immunology, The Children's Hospital of Philadelphia Department of Pediatrics, University of Pennsylvania School of Medicine
Correspondence: Jonathan M Spergel Division of Allergy and Immunology, The Children's Hospital of Philadelphia, Wood Center, 34th Street and Civic Ctr Blvd, Philadelphia, PA 19104, USA

Tel +l 2155902549

Fax + I 2155904529

Email spergel@email.chop.edu
Abstract: Atopic eczema is a common pediatric skin disorder. This review examines the use of pimecrolimus cream in the treatment of acute and chronic stages of the disease. The standard therapy is the treatment of acute flares with topical medications including pimecrolimus. The use of pimecrolimus cream for the first sign and symptoms of atopic eczema reduces the occurrence of flares as defined by the need for topical corticosteroids. The side effects of pimecrolimus cream are mild without any increase of infections or systemic immune suppression.

Keywords: pimecrolimus, atopic eczema, long-term management

\section{Introduction}

Atopic eczema (AE) (atopic dermatitis) is a common, inflammatory skin disorder that adversely affects many aspects of patients' lives. The prevalence of AE among children is $18.1 \%$ in Italy, $20.6 \%$ in Norway, $14.4 \%$ in Denmark, and $17.2 \%$ in the United States ${ }^{1-4}$ making it one of the most common pediatric skin disease. The International Study of Asthma and Allergies in Childhood (ISAAC) Phase 3 study found that AE prevalence was stabilizing or decreasing in developed countries (New Zealand, Ireland, Sweden, Germany, United Kingdom) but still increasing in developing countries (Mexico, Chile, Kenya, Algeria, and 7 countries in Southeast Asia). ${ }^{5}$

$\mathrm{AE}$ is also the start of the Atopic March, which is the natural progression of allergies from the skin to the nose and lung. Approximately 30\% to 50\% of children with AE will develop asthma and $75 \%$ will develop allergic rhinitis. ${ }^{6}$ Environmental and genetic evidence points to a defect in the skin barrier as a major contributor to the onset of AE and progression of the atopic march. The defect in the epithelial barrier of the skin may in part be due to mutations in the filaggrin gene, a key protein in the formation of the skin barrier. It is now hypothesized that improvement in the skin barrier will prevent the progression of AE to asthma.,

\section{Clinical presentation of AE}

AE typically presents in the first years of life with greater than $90 \%$ diagnosed in the first 5 years. AE is a clinical diagnosis and not a laboratory or histological diagnosis based on classic criteria of major and minor criteria (Tables 1 and 2). The classic distribution of these lesions varies with age: in infancy through early childhood, face, extensor and exposed skin surfaces are involved. In older children, flexural surfaces are more characteristically affected. In adults, the face, neck, chest, hands, and feet areas can also be affected. Other hallmarks include xerosis (dry skin) and pruritus, 
Table I Atopic eczema diagnostic criteria ${ }^{63}$

\begin{tabular}{l} 
Major features \\
I. Pruritis \\
2. Typical morphology and distribution: \\
$\quad$ a. Flexural lichenification or linearity in adults \\
$\quad$ b. Facial and extensor involvement in infant and children \\
3. Chronic or chronically relapsing dermatitis \\
4. Personal or family history of atopy (asthma, allergic rhinitis, atopic eczema) \\
Minor features \\
1. Xerosis \\
2. Ichthyosis/palmar hyperlinearity/keratosis pilaris \\
3. Immediate (type I) skin test reactivity \\
4. Elevated serum IgE \\
5. Early age of onset \\
6. Tendency toward cutaneous infection/impaired cell-mediated immunity \\
7. Tendency toward nonspecific hand or foot dermatitis \\
8. Nipple eczema \\
9. Cheilitis \\
10. Recurrent conjunctivitis \\
II. Dennie-Morgan infraorbital fold \\
12. Keratoconus \\
13. Anterior subcapsular cataracts \\
14. Orbital darkening \\
15. Facial pallor/facial erythema \\
16. Pityriasis alba \\
17. Anterior neck folds \\
18. Itch when sweating \\
19. Intolerance to wool and lipid solvents \\
20. Perifollicular accentuation \\
21. Food allergy \\
22. Course influenced by environmental/emotional factors \\
23. White dermatographism/delayed blanch \\
\hline
\end{tabular}

resulting in a vicious itch-scratch cycle. Excoriations may be apparent and, in the chronic state, result in lichenification of the skin. Recurrent skin infections by bacteria, viruses, and dermatophytes may also occur.

\section{Pathogenesis of AE}

Although the etiology of the disease is incompletely understood, AE is considered the product of complex interactions among the host's environment, susceptibility genes, skin barrier dysfunction, and local and systemic immune system dysregulation, extensively reviewed by Bieber. ${ }^{9}$ Briefly, breakdown of the skin barrier is recognized to be important in the development of AE; however, it is debated whether this event is secondary to the inflammatory response to irritants and allergens ("inside-outside hypothesis") or whether the barrier damage itself drives disease activity ("outside-inside hypothesis"). ${ }^{10}$ Clinical data have indicated that the extent of disease activity is correlated with skin barrier function. ${ }^{11}$

The skin interaction with the underlying immune system is the next key step in the pathogenesis of AE. For the start of the allergic response in $\mathrm{AE}$, allergen-specific IgE binds to mast cells in the skin through the high-affinity Fc receptor I (FceRI), resulting in mast-cell degranulation and the release of inflammatory mediators. During this process, the production of IgE by B cells depends on the support of T-helper 2 (Th2) cells. ${ }^{12}$ The initial, acute phase of $\mathrm{AE}$ is thought to be dominated by Th2 cytokines, whereas the chronic stage is thought to be T-helper 1 (Th1)-dominated; ${ }^{13-15}$ however, there also is evidence that regulatory $\mathrm{T}$ (Treg) cells may play a role in the latter stage ${ }^{16}$ in the control of the chronic inflammation.

\section{Triggers of AE}

Triggers can vary among patients, but commonly include detergents, soaps, toiletries containing alcohol or astringents, assorted chemicals, infectious agents, aeroallergens (eg, dust mites, animal dander), and certain foods.$^{17}$ Both food and environmental allergens have been implicated as offending agents in $\mathrm{AE}$, but the incidence is variable among pediatric and adult populations. In adults, less than $2 \%$ of AE patients have a food allergy as an exacerbating factor. ${ }^{18}$ In contrast, $10 \%$ to $33 \%$ of severe AE cases have an associated food allergy in infants and young children. ${ }^{19,20}$ The more severe AE is more likely that a food allergy exists and is a contributing factor. Thus, the diagnosis of a food allergy should be considered in young children who have generalized or severe $\mathrm{AE}$, or those who have recalcitrant disease despite aggressive therapy. Milk, soy, egg, peanut, and wheat accounted for $90 \%$ of food allergies implicated in AE. ${ }^{21}$ Elimination of offending foods can result in clinical improvement of AE. ${ }^{22}$ In addition to foods, environmental aeroallergens can also be significant triggers in AE. Aeroallergens may be more important in older children and adults, as these populations are more likely to have become sensitized. More than $85 \%$ of adults with AE have evidence of IgE-mediated hypersensitivity to environmental allergens. ${ }^{23}$ In children with AE, IgE-mediated aeroallergen sensitization first appears between the ages of 2 to 5 years, and predominates over food allergies by age $5 .{ }^{24}$ However, in many patients, aeroallergen sensitization is only relevant for allergic rhinoconjunctivitis and not atopic dermatitis. Nevertheless, in a subset of atopic dermatitis patients inhalational or topical exposures to aeroallergens can exacerbate AE. ${ }^{25,26}$

\section{Treatment of AE}

The basic treatment of $\mathrm{AE}$ is good skin care and avoidance of the allergens, triggers and irritants. Basic skin care involves hydration and moisturization of the skin. The review will focus 
Table 2 Atopic eczema in infancy diagnostic criteria ${ }^{63}$

\section{Major features}

I. Pruritic dermatitis

2. Typical facial or extensor eczematous or lichenified dermatitis

3. Family history of atopy (asthma, allergic rhinitis, atopic eczema)

Minor features

I. Xerosis/ichthyosis/hyperlinear palms

2. Perifollicular accentuation

3. Chronic scalp scaling

4. Peri-auricular fissures on the use of anti-inflammatory medication in the treatment of AE. During an acute infection, appropriate antibiotics can be used to treat the infectious trigger. However, the natural history of eczema has intermittent flares with erythema and increased pruritus. The treatment of flares involves the use of anti-inflammatory agents. The classic agent is topical corticosteroids (TCS). TCSs have been the predominant first-line treatment for moderate to severe AE for several decades. ${ }^{27,28}$ The potencies of TCSs range from very mild to very strong, and the choice among formulations is tailored to the severity of the disease and exacerbation and the area of the body that is affected. Cutaneous, potency-related side effects (eg, skin atrophy, striae, telangiectasias, acne rosacea, and perioral dermatitis) limit the long-term use of these agents. ${ }^{29}$ However, their long-term application can be problematic in children because of the potential for side effects, particularly skin atrophy and hypothalamic-pituitary-adrenal (HPA)-axis suppression with extensive use of high-potency topical corticosteroids. ${ }^{30,31}$ Another potential problem with TCS is compliance, as many patients and parents express concerns regarding the prolonged use of these agents. ${ }^{32}$

Therefore, in the last 10 years, two non-steroidal anti-inflammatory therapies have been developed and approved in the form of two topical calcineurin inhibitorspimecrolimus cream (Elidel ${ }^{\circledR}$, SDZ ASM 981; Novartis) and tacrolimus ointment (Protopic ${ }^{\circledR}$, FK 506; Astellas Pharma). Pimecrolimus is available as a $1 \%$ cream and is approved in the US and Europe for the treatment of mild to moderate AE, in children over 2 years of age; in approximately 40 countries, pimecrolimus is also available for the treatment of infants (3 to 23 months of age). ${ }^{33}$ Tacrolimus ointment is approved for the treatment of moderate to severe $\mathrm{AE}$ and is available as an ointment in two concentrations: $0.03 \%$ and $0.1 \%$ for the treatment of adults, and $0.03 \%$ for the treatment of children aged 2 to 15 years. $^{34}$

Both compounds bind with high affinity to the macrophilin-12 receptor and inhibit calcineurin, a calcium-dependent phosphatase that is required for activation of the nuclear factor of activated $\mathrm{T}$ cells (NF-AT). The inactive form of nuclear factor of activated $\mathrm{T}$ cells cannot enter the nucleus. Therefore, via blockage of NF-AT, these agents inhibit the inflammatory cascade produced pathologic $\mathrm{T}$ cells inhibiting expression of cytokines (IL-2, IL-4, IL-5, IL-10 and interferon-gamma). ${ }^{35}$

Pimecrolimus, in addition to preventing expression of pro-inflammatory cytokines and the proliferation of T cells, also inhibits activation of co-receptors required for T-cell activation and prevents the release of inflammatory mediators from mast cells. Unlike TCSs and tacrolimus, pimecrolimus does not induce apoptosis in Langerhans cells. ${ }^{35,36}$

\section{Clinical evidence}

More than 3000 patients were treated with pimecrolimus for up to 2 years in clinical trials..$^{37,38}$ in both adult and pediatric populations. The trials were designed in two basic schemes, one treating acute flares in 6-week double-blind placebocontrol study and the second scheme was the treatment at the first sign of inflammation in a pro-active fashion to prevent acute flares of atopic dermatitis. ${ }^{39}$ Improvement in AE was measured by three basic methods, Eczema Area Severity Index (EASI), Investigators' Global Assessment (IGA) and reduction of flares needing topical corticosteroids. The EASI is a validated composite score comprising severity ratings of erythema, oedema/induration/papulation, excoriations and lichenification weighted according to the estimated percentage of affected body surface area (BSA) of each body region. For each body region (head/neck, upper limbs, trunk and lower limbs), an affected area score of 0 to 6 was assigned for the percentage of affected BSA ( $0 \%$ to $100 \%)$. The individual ratings for erythema, edema/induration/ papulation, excoriations and lichenification were then added ( 0 to 3 for each of the four symptoms) before the sum of the individual symptoms (maximum $=12$ ) was multiplied by the affected area score (maximum $=6$ ) to give a maximum of 72 . The head/neck subtotal was multiplied by 0.1 , the upper limb subtotal by 0.2 , the trunk subtotal by 0.3 , and the lower limb subtotal by 0.4 before being summed (maximum EASI $=72) .{ }^{40}$ The IGA is a physician assigned clinical score that ranges from 0 to 5 (none to very severe) on the physician determination of AE severity.

The pediatric trials have shown short-term efficacy in patients randomized $2: 1$ to 6 week trial of pimecrolimus treatment or vehicle followed by 20 -week open label extension in children young as 3 months of age (Table 3 ). In the trial of 403 children and young adults (aged 1 to 17 years with 
Table 3 Pimecrolimus pediatric trials

\begin{tabular}{lllll}
\hline Author & No patients & Study design & Duration & Measurement \\
\hline Eichenfield $^{41}$ & 403 & Randomized/open label & 6 weeks/20 weeks & EASI, IGA \\
$\mathrm{Ho}^{42}$ & 186 & Randomized/open Label & 6 weeks/20 weeks & EASI, IGA \\
Kapp $^{39}$ & 251 & Randomized & I year & Flares, EASI, IGA \\
Papp $^{45}$ & 81 & Randomized/open label & I year/l year & EASI, IGA, Flare \\
Wahn $^{44}$ & 713 & Randomized & I year & EASI, flare \\
\hline
\end{tabular}

Abbreviations: EASI, Eczema Area Severity Index; IGA, Investigators' Global Assessment, IGA.

an IGA score at baseline of 2 or 3 [mild or moderate AD]), ${ }^{41}$ $35 \%$ of the children treated with pimecrolimus were clear or almost clear of AE at 6 weeks, compared $18 \%$ children treated with the vehicle $(\mathrm{p}<0.05)$. In the same trial, $60 \%$ of pimecrolimus-treated patients showed at least a one-point reduction in the IGA score by 6 weeks compared to $33 \%$ of vehicle-treated patients. ${ }^{41}$ In the infant trial of 186 patients with a baseline IGA score of 2 or 3 (mild or moderate AE), ${ }^{39}$ in addition to the other two pimecrolimus-treated patients showed significant improvement in IGA scores compared to placebo at the end of 6 week blinded trial. Similarly in another infant trial, $55 \%$ of the pimecrolimus-treated patients were almost or clear $(\mathrm{IGA}=1$ or 0$)$ compared to $24 \%$ in vehicle group. ${ }^{42}$ The adult trials were of similar design with 130 adults and open labeled study of 947 of patients from 3 months to 81 years of age (Table 4$).{ }^{43-45}$ In the adult trial, IGA scores also significantly improved in pimecrolimus group compared to placebo.

\section{Pruritus}

One of the clinical features of AE is intense pruritus. AE is often called the itchy skin that rashes. Pimecrolimus cream $1 \%$ showed improvement in pruritus by the eighth day in the infant in $70 \%$ of the children compared to $37 \%$ of the children treated with vehicle $(\mathrm{p}<0.001)$. A similar effect was noted in children and adolescents, with $44 \%$ of pimecrolimustreated patients reporting no (0) or mild (1) pruritus at Day 8 , compared with $26 \%$ of vehicle-treated patients $(p<0.001) .{ }^{46}$
In the adult trial of 130 patients, self-assessed pruritus severity scores had improved by at least 1 point (4-point scale of 0 to 3 ) in $45 \%$ of patients treated with pimecrolimus compared with $17 \%$ of those using vehicle $(p=0.0016) .{ }^{47}$ A significant treatment effect was also observed shortly after initiating pimecrolimus treatment even in a group of eczema patients with moderate to severe pruritus. Within 2 days, $42 \%$ of pimecrolimus-treated compared with $27 \%$ of vehicle-treated patients scored their pruritus as mild or absent (pruritus score of 0 or $1 ; \mathrm{p}=0.040$ ), and these treatment differences were maintained throughout the study. ${ }^{48}$

\section{Erythema/inflammation}

The other cardinal features of AE are erythema and inflammation. In one study of moderate $\mathrm{AE}$ in the adults, signs and symptoms improved progressively throughout the first 6 weeks of treatment, with a 33\% reduction in EASI scores after the first 7 days and eczema score improved by $69.8 \%$ at the end of 6 weeks. In comparison, the patients treated with vehicle group had worsening eczema evidenced by an increase by $3.8 \%$ after 1 week and at Week 6 at $15.9 \%$ (Figure 1). ${ }^{47}$

In the pediatric trials, improvement in eczema severity is also noted by changes in EASI scores. Pimecrolimustreated patients with improvement within 1 week continued to improve during the length of the study (Figure 2). Young children and adolescents showed improvements for each measure: for example, erythema; $61 \%$ of pimecrolimus-treated

Table 4 Pimecrolimus adult trials

\begin{tabular}{lllll}
\hline Author & No patients & Study design & Duration & Measurement \\
\hline Gollnick $^{64}$ & 266 & Randomized/placebo & 26 weeks & Flare, IGA \\
Meurer $^{65}$ & 192 & Randomized/placebo & 24 weeks & Flares, IGA \\
Meurer $^{47}$ & 130 & Randomized/placebo & 24 weeks & Flares, IGA \\
Luger $^{59}$ & 658 & Randomized pimecrolimus/TCS & 52 weeks & Safety \\
Kaufmann $^{48}$ & 198 & Randomized/placebo & 7 days & Pruritus \\
\hline
\end{tabular}

Abbreviations: IGA, Investigators' Global Assessment; TCS, topical corticosteroids. 


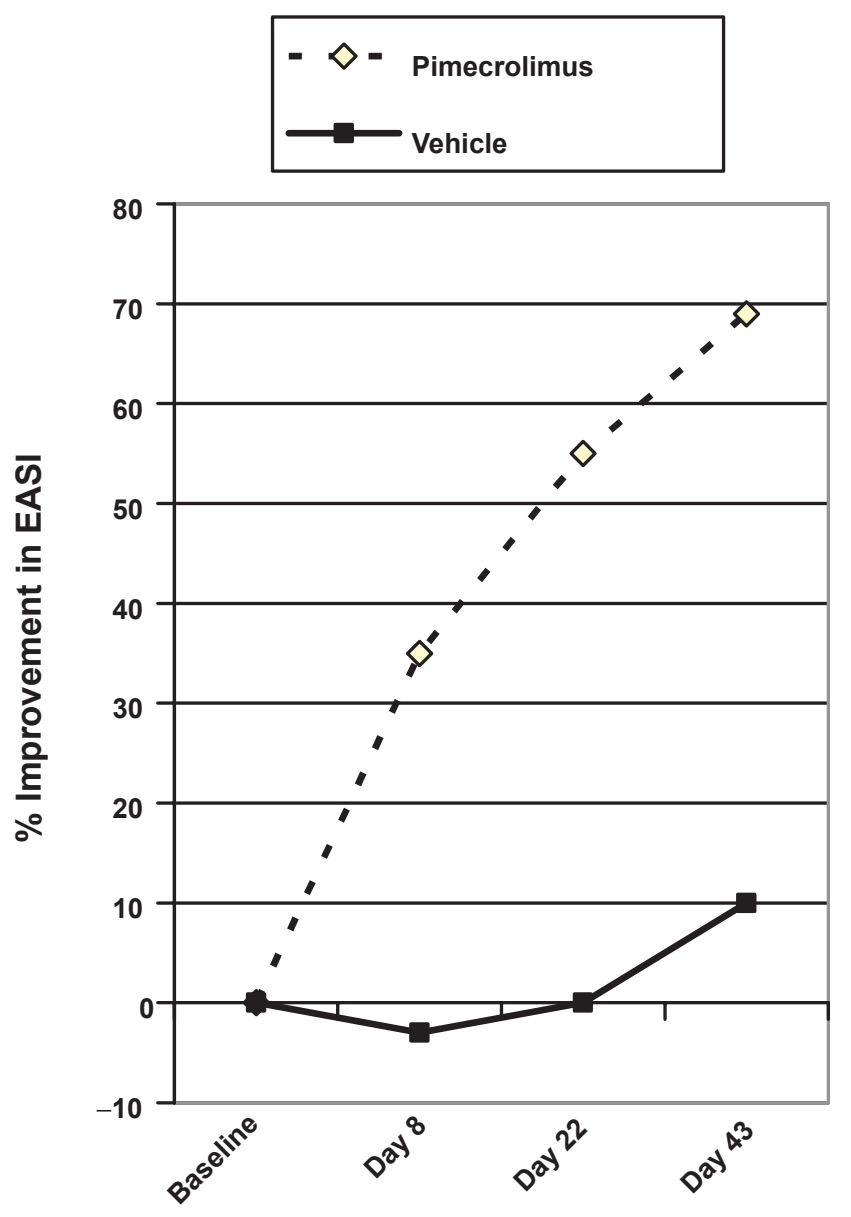

Figure I Median percentage change in Eczema Area Severity Index (EASI) over time for pimecrolimus compared with vehicle. Drawn from data of Meurer et al. ${ }^{43,47}$

versus $37 \%$ of vehicle-treated at 6 weeks. ${ }^{41}$ The improvement in eczema severity occurred in all age groups, including infants. Pimecrolimus reduced the signs of inflammation (erythema and infiltration) by 8 days in the infant trial. $61 \%$ of the patients treated with pimecrolimus had no or only mild erythema on all body areas, compared with $27 \%$ of patients treated with vehicle $(\mathrm{p}<0.001)$. For infiltration, $67 \%$ patients treated with pimecrolimus had no or only mild symptoms on all body areas, compared with $40 \%$ in the vehicle group in the same infant trial. ${ }^{42}$

As mentioned earlier, patients also had short-term improvement in IGA scores. Long-term improvement was noted in a trial of 947 patients in a 1-year open-labeled study, aged from 3 months to 81 years; improvements in IGA were noted by 8 days in the total population. ${ }^{43,49}$ In the same study, 394 patients enrolled with moderate disease; $18 \%$ improved to IGA of 0 or 1 by 1 week, rising to $42 \%$ at day 168 . With a similar study of 262 children with moderate eczema $(\mathrm{IGA}=3)$ at baseline, $34.7 \%$ were clear or almost clear of eczema after 1 year of open-labeled treatment. ${ }^{44}$ For the 87 children with severe/very severe AE $(\mathrm{IGA}=4 / 5)$ at baseline, $18.4 \%$ were clear or almost clear of $\mathrm{AE}$ at 1 year, $19.5 \%$ had mild eczema (IGA $=2)$ and $31 \%$ improved to moderate disease $(\mathrm{IGA}=3)$. These results indicate that all patients within varying severity can improve with pimecrolimus treatment.

\section{Prevention of flares}

$\mathrm{AE}$ is a chronic disease with periods of relapse and flares. Several trials examined the use of pimecrolimus form the start of symptoms to prevent flares in year-long trials in and children and adolescents. The use of pimecrolimus creams decreased over the year in both trials, indicating overall control with pimecrolimus. The total body surface area affected by eczema decreased over a year-long open-label trial from $24 \%$ to $7 \%$ in children/adolescent trial..$^{50}$ The time to first flare was substantial longer in the pimecrolimustreated group compared to the vehicle treated group. In fact, $61 \%$ of children and adolescents in the pimecrolimus group were flare-free for 6 months and 51\% were flare-free for 12 months of treatment, which is significantly more than the vehicle-treated group, as only $34 \%$ of patients in the control group at 6 months and $28 \%$ at 12 months were flare-free. ${ }^{44}$ For the infants and toddlers, $68 \%$ were flare-free for 6 months of treatment, and $57 \%$ were flare-free for 12 months of treatment in the pimecrolimus-treated group. In contrast, in the control group, $30 \%$ and $28 \%$ of patients completed 6 and 12 months of treatment without flares, respectively. ${ }^{39}$ In similar studies with pimecrolimus in adults, the prevention of flares can also be observed. In an identical designed trial but of 24 weeks' duration, more adults patients with moderate $\mathrm{AE}$ treated with pimecrolimus remained in remission and experienced no major flares compared to vehicle group (pimecrolimus/ vehicle: $59.7 \%$ vs $22.1 \%, \mathrm{p}=0.001) .{ }^{47}$

\section{Long-term treatment of AE}

The alternative strategy to prevent flares is to use medications in a preventative fashion, as in in asthma, another atopic disease. Several recent trials have tried this strategy of medication on a regular basis 2 to 4 times a week to prevent flares even before the start of symptoms. Studies have examined both the use of topical steroids (fluticasone) or tacrolimus ointment three times a week to reduce the incidence of flares (Table 5). 348 patients (231 children, 117 adults) were randomized at a 2:1 ratio to either intermittent fluticasone propionate (FP) or vehicle, once daily 4 days per week for 4 weeks followed by once daily 2 days per week for 16 weeks. 


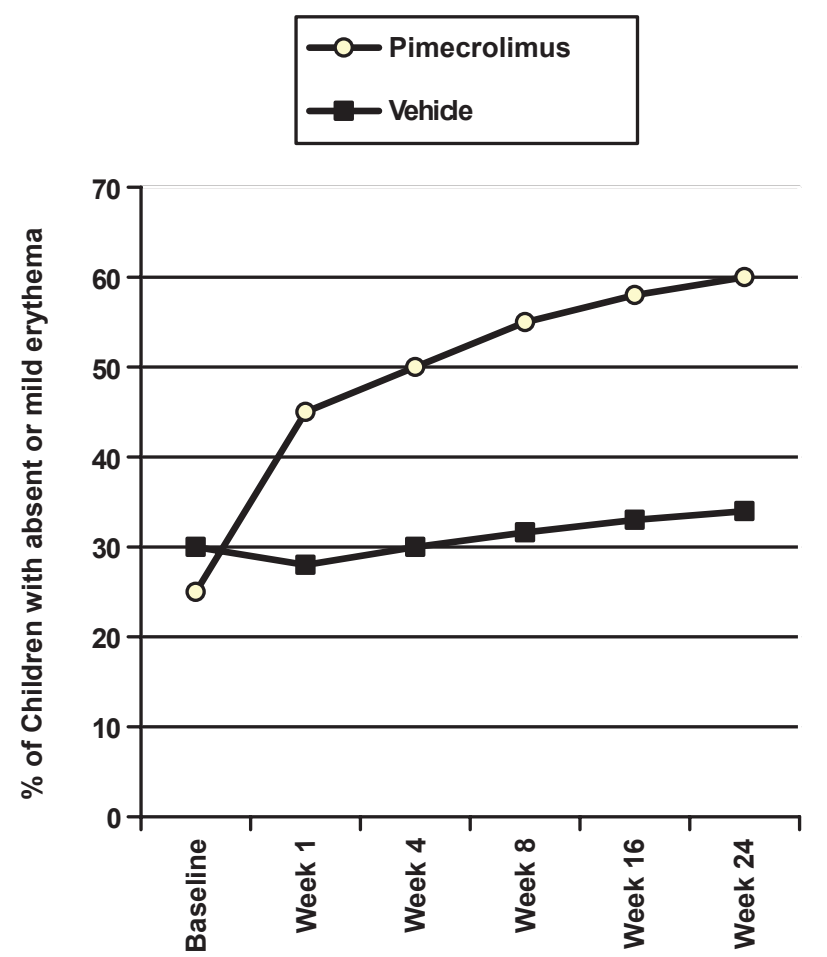

Figure 2 Percentage of children with mild or absent erythema scores. Drawn from data of Eichenfield et al. ${ }^{41}$

The patients on the active therapy were 7.7 times less likely to have a AE flare. ${ }^{51} \mathrm{~A}$ second trial of similar design examined FP 2 days week compared to placebo for prevention of flares in 295 patients ( 12 to 65 years of age). The time to first relapse was 6 weeks for placebo compared to 16 weeks for FP. ${ }^{52}$ In the Breneman study with tacrolimus three times a week, 197 adult patients were randomized to tacrolimus (125) and vehicle (72). The tacrolimus had more flare-free days ( 177 for tacrolimus and 134 for vehicle, $p=0.003$ ). Also, the time for first relapse was 169 days for tacrolimus and 43 for vehicle, significantly better for the active therapy $(\mathrm{p}=0.037){ }^{53}$ A similar study in pediatrics showed a significant effect of 105 patients using tacrolimus three times a week compared to placebo after 16 -week open-label run-in with $0.03 \%$ tacrolimus ointment. The patients on tacrolimus arm had significantly more disease-free days and longer time to first relapse. ${ }^{54}$ The third tacrolimus study examined 224 adults randomized to either tacrolimus or placebo twice a week to prevent flares. The active therapy (tacrolimus) increased the time to first flare from 15 to 142 days compared to placebo treatment. ${ }^{55}$ The fourth study examined 250 children randomized to either tacrolimus or placebo twice a week to prevent flares. Similar to adult study, the active therapy (tacrolimus) increased the time to first flare from 38 days to 178 days.
Also, the number of flares decreased in tacrolimus group compared to placebo. ${ }^{56}$

\section{Safety}

For the use of any medications, the issue of safety is important (both local and systemic). For topical calcineurin inhibitors, the local side effects would be confined to the skin. During randomized trials using pimecrolimus, the most commonly reported form of application-site reaction in children and adults was a sensation of burning at the application site. Interestingly, it was reported at a similar rate in both vehicleand pimecrolimus-treated children (10.4\% of pimecrolimustreated versus $12.5 \%$ of vehicle-treated patients). ${ }^{41}$

For the systemic side effects, pimecrolimus would need to be absorbed at high levels. However, the use of pimecrolimus cream in $\mathrm{AE}$ does not lead to any significant levels in the circulating blood system. In pharmacokinetic studies of children with moderate to severe AE with up to $92 \%$ BSA affected, $67 \%$ of samples had pimecrolimus blood concentrations below $0.5 \mathrm{ng} / \mathrm{mL}$ and $97 \%$ of blood concentrations were in the range of 0.5 to $2.0 \mathrm{ng} / \mathrm{mL}$. Also, for rat, pig, and human skin, pimecrolimus demonstrated a 9- to 10-fold lower permeation through skin in vitro than tacrolimus when comparing identical solutions of both compounds. ${ }^{36}$ Patients treated with pimecrolimus in the $\mathrm{AD}$ trial have normal $\mathrm{T}$ and B cell function as evidenced by response to vaccination and delayed hypersensitivity response. Cell-mediated, delayed-type hypersensitivity (DTH) reaction against a range of antigens is a common method of assessing immunocompetence. DTH testing was used to test immune function in one study of pimecrolimus cream $1 \%$ with a total of 112 subjects who completed 1 year of treatment (82 pimecrolimus cream 1\%; 30 vehicle). ${ }^{44}$ Pimecrolimus had no effect on DTH testing with similar response to that of the placebo group.

Skin infections are another concern. Patients with $\mathrm{AE}$ are more prone to skin infections: Staphylococcus aureus and viral infections, including herpes simplex, herpes zoster, Epstein-Barr virus, molluscum contagiosum, and human papilloma virus. ${ }^{57,58}$ Skin infections were investigated in 1-year study comparing pimecrolimus and triamcinolone acetonide $0.1 \%$ cream in 658 adults. ${ }^{59}$ Pimecrolimus was not associated with an increase in bacterial or fungal skin infections, or in herpes simplex or herpes zoster infections compared to triamcinolone. In the pediatric trials, there were no significant differences in overall incidence of skin infections after pimecrolimus treatment in infants or children. In a 2-year open-label trial, the frequency of skin infections did not change over time, as the incidence of skin infections 
Table 5 Long-term treatment trials for atopic eczema

\begin{tabular}{|c|c|c|c|c|}
\hline Author & Duration & No patients & Endpoint & Treatment arms \\
\hline Berth-Jones $^{52}$ & $\begin{array}{l}16 \text { weeks, randomized } \\
\text { placebo controlled }\end{array}$ & 295 & Flares & Fluticasone/placebo 2 days a week \\
\hline Hanifin ${ }^{52}$ & $\begin{array}{l}16 \text { weeks, randomized } \\
\text { placebo controlled }\end{array}$ & 348 & Flares & Fluticasone/placebo 4 days a week \\
\hline Breneman $^{53}$ & $\begin{array}{l}52 \text { weeks, randomized, } \\
\text { placebo controlled. }\end{array}$ & 197 & Onset of Ist flare & Tacrolimus/placebo 3 days a week \\
\hline Paller ${ }^{54}$ & $\begin{array}{l}40 \text { weeks, randomized, } \\
\text { placebo controlled }\end{array}$ & 105 & Disease-free days & Tacrolimus/placebo 3 days a week \\
\hline Wollenberg ${ }^{55}$ & $\begin{array}{l}52 \text { weeks, randomized } \\
\text { placebo controlled }\end{array}$ & 224 & Onset of Ist flare & Tacrolimus/placebo 2 days a week \\
\hline Thaci $^{56}$ & $\begin{array}{l}52 \text { weeks, randomized, } \\
\text { placebo controlled. }\end{array}$ & 250 & Onset of Ist flare & Tacrolimus/placebo 2 days a week \\
\hline
\end{tabular}

was comparable in the first and second years of treatment. Compared with control treatments, the incidence of all bacterial and viral infections with pimecrolimus in infants treated for more than 1 year was low. ${ }^{60,61}$ Overall, pimecrolimus cream has demonstrated low systemic absorption and a low incidence of systemic adverse events in children and adults.

Pimecrolimus was issued a black box warning in 2006 due to concerns about incidence of lymphoma. This warning was based on hypothetical concerns about pimecrolimus causing Epstein-Barr virus induced lymphoproliferation disease (lymphoma) or skin cancer. This warning was reviewed by many academic allergy and dermatology societies with the feeling that it was not warranted. The joint task force from the American Academy of Allergy Asthma and Immunology and American College of Allergy Asthma and Immunology found that the risk-benefit ratio of topical pimecrolimus and tacrolimus are similar to that of most conventional therapies for the treatment of chronic relapsing eczema. The panel concluded that

1. Lymphoma formation is generally associated with high dose and sustained systemic exposure to pimecrolimus and tacrolimus.

2. The reported cases of lymphoma from topical pimecrolimus and tacrolimus are not consistent with lymphomas observed with systemic immunomodulator therapy.

3. The actual rate of lymphoma formation reported to date for topical calcineurin inhibitors is lower than predicted in the general population.

In large-scale pharmacologic database studies of over 250,000 patients, no increase in the incidence with pimecrolimus was noted for lymphoma. ${ }^{62}$ The risk of lymphoma does not seem to be an issue for patient using pimecrolimus cream.

\section{Conclusion}

Pimecrolimus cream is a safe and effective therapy for the treatment of atopic dermatitis. One of the key components of $\mathrm{AE}$ is itch and inflammation. Both elements are relieved within 1 week of pimecrolimus treatment. One of the novel potential uses of pimecrolimus cream in the treatment of $\mathrm{AE}$ is the use of proactive therapy. The use of pimecrolimus cream at the first signs and symptoms of AE flare reduces the need for topical steroids. Finally, pimecrolimus cream appears to be safe in both long- and short-term trials with equivalent or superior safety profile to topical corticosteroids.

\section{Disclosures}

The author discloses no conflicts of interest.

\section{References}

1. Peroni DG, Piacentini GL, Bodini A, Rigotti E, Pigozzi R, Boner AL. Prevalence and risk factors for atopic dermatitis in preschool children. Br J Dermatol. 2008;158(3):539-543.

2. Smidesang I, Saunes M, Storro O, et al. Atopic dermatitis among 2-year olds; high prevalence, but predominantly mild disease-the PACT study, Norway. Pediatr Dermatol. 2008;25(1):13-18.

3. Kjaer HF, Eller E, Host A, Andersen KE, Bindslev-Jensen C. The prevalence of allergic diseases in an unselected group of 6-year-old children. The DARC birth cohort study. Pediatr Allergy Immunol. 2008;19(8):737-745.

4. Laughter D, Istvan JA, Tofte SJ, Hanifin JM. The prevalence of atopic dermatitis in Oregon schoolchildren. J Am Acad Dermatol. 2000;43(4):649-655.

5. Williams H, Stewart A, von M, Cookson W, Anderson H. Is eczema really on the increase worldwide? J Allergy Clin Immun. 2008;121(4):947-954.

6. Spergel JM, Paller AS. Atopic dermatitis and the atopic march.J Allergy Clin Immunol. 2003;112(6 Suppl):S118-127.

7. Palmer CN, Irvine AD, Terron-Kwiatkowski A, et al. Common loss-of-function variants of the epidermal barrier protein filaggrin are a major predisposing factor for atopic dermatitis. Nat Genet. 2006;38(4):441-446.

8. Weidinger S, O’Sullivan M, Illig T, et al. Filaggrin mutations, atopic eczema, hay fever, and asthma in children. J Allergy Clin Immunol. 2008;121(5):1203-1209 e1201. 
9. Bieber T. Atopic dermatitis. N Engl J Med. 2008;358(14):1483-1494.

10. Elias PM, Hatano Y, Williams ML. Basis for the barrier abnormality in atopic dermatitis: outside-inside-outside pathogenic mechanisms. J Allergy Clin Immunol. 2008;121(6):1337-1343.

11. Chamlin SL, Kao J, Frieden IJ, et al. Ceramide-dominant barrier repair lipids alleviate childhood atopic dermatitis: changes in barrier function provide a sensitive indicator of disease activity. J Am Acad Dermatol. 2002;47(2):198-208.

12. Bacharier LB, Geha RS. Molecular mechanisms of IgE regulation. J Allergy Clin Immunol. 2000;105(2 Pt 2):S547-S558.

13. Hamid Q, Boguniewicz M, Leung DYM. Differential in situ cytokine gene expression in acute versus chronic atopic dermatitis. J Clin Invest. 1994; $94: 870-876$.

14. Hamid Q, Naseer T, Minshall E, Song Y, Boguniewicz M, Leung D. In vivo expression of IL-12 and IL-13 in atopic dermatitis. J Allergy Clin Immunol. 1996;98:225-231.

15. Leung DYM. Atopic dermatitis: New insights and opportunities for therapeutic intervention. J Allergy Clin Immuno. 2000;105(5): $860-876$.

16. Akdis $\mathrm{M}$, Blaser $\mathrm{K}$, Akdis CA. T regulatory cells in allergy: novel concepts in the pathogenesis, prevention, and treatment of allergic diseases. J Allergy Clin Immunol. 2005;116(5):961-968; quiz 969.

17. Akdis CA, Akdis M, Bieber T, et al. Diagnosis and treatment of atopic dermatitis in children and adults: European Academy of Allergology and Clinical Immunology/American Academy of Allergy, Asthma and Immunology/PRACTALL Consensus Report. Allergy. 2006;61(8): 969-987.

18. Werfel T, Breuer K. Role of food allergy in atopic dermatitis. Curr Opin Allergy Clin Immunol. 2004;4(5):379-385.

19. Eigenmann PA, Sicherer SH, Borkowski TA, Cohen BA, Sampson HA. Prevalence of IgE-mediated food allergy among children with atopic dermatitis. Pediatrics. 1998;101(3):E8.

20. Sicherer SH, Sampson HA. Food hypersensitivity and atopic dermatitis: pathophysiology, epidemiology, diagnosis, and management. J Allergy Clin Immunol. 1999;104(3 Pt 2):S114-S122.

21. Lever R, MacDonald C, Waugh P, Aitchison T. Randomised controlled trial of advice on an egg exclusion diet in young children with atopic eczema and sensitivity to eggs. Pediatr Allergy Immunol. 1998;9(1):13-19.

22. Woodmansee DP, Christiansen SC. Improvement in atopic dermatitis in infants with the introduction of an elemental formula. J Allergy Clin Immunol. 2001;108(2):309.

23. Schmid-Grendelmeier P, Simon D, Simon HU, Akdis CA, Wuthrich B. Epidemiology, clinical features, and immunology of the "intrinsic" (non-IgE-mediated) type of atopic dermatitis (constitutional dermatitis). Allergy. 2001;56(9):841-849.

24. Wang IJ, Lin YT, Yang YH, et al. Correlation between age and allergens in pediatric atopic dermatitis. Ann Allergy Asthma Immunol. 2004;93(4):334-338.

25. Tuft L, Heck VM. Studies in atopic dermatitis. IV. Importance of seasonal inhalant allergens, especially ragweed. $J$ Allergy. 1952;23(6):528-540.

26. Tupker RA, De Monchy JG, Coenraads PJ, Homan A, van der Meer JB. Induction of atopic dermatitis by inhalation of house dust mite. $J$ Allergy Clin Immunol. 1996;97(5):1064-1070.

27. Leung DY, Nicklas RA, Li JT, et al. Disease management of atopic dermatitis: an updated practice parameter. Joint Task Force on Practice Parameters. Ann Allergy Asthma Immunol. 2004;93(3 Suppl 2): S1-S21.

28. Hughes J, Rustin M. Corticosteroids. Clin Dermatol. 1997;15(5): 715-721.

29. Furue M, Terao H, Rikihisa W, et al. Clinical dose and adverse effects of topical steroids in daily management of atopic dermatitis. $\mathrm{Br} J$ Dermatol. 2003;148(1):128-133.

30. Bode HH. Dwarfism following long-term topical corticosteroid therapy. JAMA. 1980;244(8):813-814.

31. Hill CJ, Rostenberg A Jr. Adverse effects from topical steroids. Cutis. 1978;21(5):624-628.
32. Rao VU, Apter AJ. Steroid phobia and adherence-problems, solutions, impact on benefit/risk profile. Immunol Allergy Clin North Am. 2005;25(3):581-595.

33. FDA. Elidel 1\% Cream (Pimecrolimus): Packet Insert. Washington DC: Federal Drug Adminstration; 2001.

34. Alaiti S, Kang S, Fiedler VC, et al. Tacrolimus (FK506) ointment for atopic dermatitis: a phase I study in adults and children. $J$ Am Acad Dermatol. 1998;38(1):69-76.

35. Spergel JM. Immunology and treatment of atopic dermatitis. Am J Clin Dermatol. 2008;9(4):233-244.

36. Hultsch T, Kapp A, Spergel J. Immunomodulation and safety of topical calcineurin inhibitors for the treatment of atopic dermatitis. Dermatology. 2005;211(2):174-187.

37. Eichenfield LF, Thaci D, de Prost Y, Puig L, Paul C. Clinical management of atopic eczema with pimecrolimus cream 1\% (Elidel) in paediatric patients. Dermatology. 2007;215 Suppl 1:3-17.

38. Meurer M, Lubbe J, Kapp A, Schneider D. The role of pimecrolimus cream 1\% (Elidel)) in managing adult atopic eczema. Dermatology. 2007;215 Suppl 1:18-26.

39. Kapp A, Papp K, Bingham A, et al. Long-term management of atopic dermatitis in infants with topical pimecrolimus, a nonsteroid anti-inflammatory drug. J Allergy Clin Immun. 2002;110(2): 277-284.

40. Hanifin J, Thurston M, Omoto M, Cherill R, Tofte S, Graeber M. The eczema area and severity index (EASI): assessment of reliability in atopic dermatitis. EASI Evaluator Group. Exp Dermatol. 2001; 10(1):11-18.

41. Eichenfield L, Lucky A, Boguniewicz M, et al. Safety and efficacy of pimecrolimus (ASM 981) cream $1 \%$ in the treatment of mild and moderate atopic dermatitis in children and adolescents. $J$ Am Acad Dermatol. 2002;46(4):495-504.

42. Ho V, Gupta A, Kaufmann R, Todd G, Vanaclocha F, Takaoka R, Folster-Holst R, Potter P, Marshall K, Thurston M, Bush C, Cherill R. Safety and efficacy of nonsteroid pimecrolimus cream $1 \%$ in the treatment of atopic dermatitis in infants. J Pediatr. 2003;142:155-162.

43. Meurer M, Lubbe J, Kapp A, Schneider D. The role of pimecrolimus cream 1\% (Elidel) in managing adult atopic eczema. Dermatology. 2007;215(1):18-26.

44. Wahn U, Bos JD, Goodfield M, et al. Efficacy and safety of pimecrolimus cream in the long-term management of atopic dermatitis in children. Pediatrics. 2002;110(1 Pt 1):e2.

45. Papp K, Werfel T, Folster-Holst R, et al. Long-term control of atopic dermatitis with pimecrolimus cream $1 \%$ in infants and young children: a two-year study. J Am Acad Dermatol. 2005;52:240-246.

46. Hanrahan J, Choo P, Carlson W, Greineder D, Faich G, Platt R. Terfenadine associated ventricular arrhythmias and QTc prolongation. Ann Epidemiol. 1995;5(3):201-209.

47. Meurer M, Fartasch M, Albrecht G, et al; For The CASM-DE. Study Group: Long-term efficacy and safety of pimecrolimus cream $1 \%$ in adults with moderate atopic dermatitis. Dermatology. 2004;208: 365-372.

48. Kaufmann R, Bieber T, Helgesen AL, et al. Onset of pruritus relief with pimecrolimus cream $1 \%$ in adult patients with atopic dermatitis: a randomized trial. Allergy. 2006;61:375-381.

49. Lubbe J, Degreef H, Hofmann H, et al. Clinical use of pimecrolimus cream in atopic eczema: A 6-month open-label trial in 947 patients. J Eur Acad Dermatol Venerol. 2003;17(3):183 (abstr 182.139).

50. Papp K, Staab D, Harper J, et al. Effect of pimecrolimus cream $1 \%$ on the long-term course of pediatric atopic dermatitis. Int J Dermatol. 2004:43:978-983.

51. Hanifin J, Gupta AK, Rajagopalan R. Intermittent dosing of fluticasone propionate cream for reducing the risk of relapse in atopic dermatitis patients. Br J Dermatol. 2002;147(3):528-537.

52. Berth-Jones J, Damstra RJ, Golsch S, et al. Twice weekly fluticasone propionate added to emollient maintenance treatment to reduce risk of relapse in atopic dermatitis: randomised, double blind, parallel group study. BMJ. 2003;326(7403):1367. 
53. Breneman D, Fleischer AB Jr, Abramovits W, et al. Intermittent therapy for flare prevention and long-term disease control in stabilized atopic dermatitis: a randomized comparison of 3-times-weekly applications of tacrolimus ointment versus vehicle. J Am Acad Dermatol. 2008;58(6):990-999.

54. Paller AS, Eichenfield LF, Kirsner RS, Shull T, Jaracz E, Simpson EL. Three times weekly tacrolimus ointment reduces relapse in stabilized atopic dermatitis: a new paradigm for use. Pediatrics. 2008;122(6): e1210-e1218.

55. Wollenberg A, Reitamo S, Atzori F, et al. Proactive treatment of atopic dermatitis in adults with $0.1 \%$ tacrolimus ointment. Allergy. 2008;63(6):742-750.

56. Thaci D, Reitamo S, Gonzalez Ensenat MA, et al. Proactive disease management with $0.03 \%$ tacrolimus ointment for children with atopic dermatitis: results of a randomized, multicentre, comparative study. Br J Dermatol. 2008;159(6):1348-1356.

57. Bonifazi E, Garofalo L, Pisani V, Meneghini CL. Role of some infectious agents in atopic dermatitis. . Acta Derm Venereo. 1985;114:98-100.

58. Rystedt I, Strannegard, IL, Strannegard, O. Recurrent viral infections in patients with past or present atopic dermatitis. $\mathrm{Br} J$ Dermatol. 1986;114:575-582.
59. Luger T, Lahfa M, Folster-Holst R, et al. Long-term safety and tolerability of pimecrolimus cream $1 \%$ and topical corticosteroids in adults with moderate to severe atopic dermatitis. J Dermatolog Treat. 2004;15:1-10.

60. Paul C, Cork M, Rossi AB, Papp KA, Barbier N, de Prost Y. Safety and tolerability of $1 \%$ pimecrolimus cream among infants: experience with 1133 patients treated for up to 2 years. Pediatrics. 2006;117:e118-e128.

61. Eichenfield L, Thacib T, de Prostc Y, Puigd L, Paule C. Clinical Management of Atopic Eczema with Pimecrolimus Cream 1\% $\left(\right.$ Elidel $\left.^{\circledR}\right)$ in Paediatric Patients. Dermatology. 2007;215(1):3-17.

62. Arellano F, Wentworth CE, Arana A, Fernandez C, Paul CE. Risk of lymphoma following exposure to calcineurin inhibitors and topical steroids in patients with atopic dermatitis. J Invest Dermatol. 2007;127:808-816.

63. Hanifin J, Rajka G. Diagnostic features of atopic dermatitis. Acta Derm Venereol. 1980;92:44-47.

64. Gollnick H, Kaufmann R, Stough D, et al. Pimecrolimus cream 1\% in the long-term management of adult atopic dermatitis: prevention of flare progression. A randomized controlled trial. $\mathrm{Br} J$ Dermatol. 2008;158(5):1083-1093.

65. Meurer M, Folster-Holst R, Wozel G, Weidinger G, Junger M, Brautigam M. Pimecrolimus cream in the long-term management of atopic dermatitis in adults: a six-month study. Dermatology. 2002;205(3):271-277.
Clinical, Cosmetic and Investigational Dermatology

\section{Publish your work in this journal}

Clinical, Cosmetic and Investigational Dermatology is an international, peer-reviewed, open access, online journal that focuses on the latest clinical and experimental research in all aspects of skin disease and cosmetic interventions. All areas of dermatology will be covered; contributions will be welcomed from all clinicians and

\section{Dovepress}

basic science researchers globally. This journal is indexed on CAS The manuscript management system is completely online and includes a very quick and fair peer-review system, which is all easy to use. Visit http://www.dovepress.com/testimonials.php to read real quotes from published authors. 